\title{
Brazilian Oral Research: Combining Scientific Excellence and Social Impact
}

Ana Estela Haddad

PhD, Professor, Department of Orthodontics and Pedodontics, School of Dentistry, University of São Paulo and Director of Health Management Education, Ministry of Health
$\mathbf{T}^{\mathrm{s}}$ he SBPqO offered a workshop in Oral Research and Public Health Policy, in its $24^{\text {th }}$ Annual Meeting held in 2007. The workshop was held in partnership with the Health Education Management Department (DEGS/SGTES) of the Ministry of Health, and attended by several renowned researchers.

Brazilian scientific production has increased significantly in the past decades, and scientific production in the field of health has also seen marked growth, placing Brazil among the 25 most productive countries in the world. Brazilian Dentistry ranks $5^{\text {th }}$ in recognized world scientific production. Brazil currently exports knowledge and technology in the health field, notably in dental health.

In spite of such remarkable advances, the impact of all this knowledge on the amelioration of health conditions, and on the assessment of health services and policies remains meager.

Listed below are some of the difficulties encountered in making the production of knowledge converge towards the needs of Brazil's Unified Health System (SUS), which were highlighted by the summary report of the workshop:

- Faculty training is divorced from the needs of the population - the graduate school system prioritizes technical-scientific training, widening the gap between future professors or researchers and the needs of the SUS.

- There is a lack of knowledge concerning the management of public funds both in health facilities and in universities, which do not emphasize research projects that address the needs of the population.

- The research being conducted is not guided toward making health care more effective, nor does it address the necessary multi-disciplinarity of the health care field, both in the SUS and in teaching clinics.

- There are not enough studies focusing on health care economics - we do not know the real costs and expenditures involved in oral health care in the public sector.

- There is a need to determine the actual burden of oral diseases in order to better organize our research needs and health services.

- Epidemiological changes have not been accompanied by the necessary changes in university curricula.

- Research is not committed to addressing the real needs of the population; the reality in the academic world is detached from the reality of providing health care services.

- There is a fear among health care providers that new demands will be created by universities without any proposals for addressing them. 
- Universities have their own internally organized services, thus hindering integration.

- Current knowledge is excessively specialized, thus hampering the development of primary care research.

A movement committed to changing this reality has begun through the implementation of a program that combines teaching and health care services, namely the National Program for Resteering Health Professional Education ("Pró-Saúde"). The report of the $2^{\text {nd }}$ National "Pró-Saúde" Seminar, in May 2008, pointed out significant shortcomings of professional education to date, particularly, that it is fragmentary, individualized, and of sole focus, thus preventing a more holistic insight into health care practice. Greater shared action can already be seen between public health network management and college faculty and undergraduate students.

Undergraduate student contact with primary health care in the public health network has led to greater awareness among both students and professors concerning its strategic importance, and has also created a greater willingness to intervene in the improvement of our health care model. Primary health care has been recognized as a privileged locus for change: It is a system where patients are kept on file, care is longitudinal, a stronger professional-patient bond is established, a systemic approach to families is taken, and a multidisciplinary health care team can operate together. This practice has attracted a greater number of students to primary care internships.

In 2006 and 2007, the Ministry of Health allocated about 40 million reals to 90 projects selected by public bid and developed in undergraduate courses. Of these, 38 were in the field of Medicine, 27 in the field of Nursing and 25 in the field of Dentistry. In 2008, the announcement of a new bid extended the "Pró-Saúde" program to another 268 undergraduate courses of 68 universities in the 14 professions encompassing the health care field.

For the upcoming second semester of 2008, the first bid for the Education Through Health Care Work Program (the "PET-Saúde") has already been called. The goals of the program include encouraging research development and creating Centers of Clinical Excellence Applied to Primary Health Care. Scholarships will be offered to students in selected projects, in the following categories: Tutorship (for college professors); Preceptorship (for health service professionals who offer counseling for teaching and learning activities for undergraduates); and Monitorship (for undergraduate students).

The Ministry of Health, together with the Ministry of Education, expects the "PET-Saúde" Program to consolidate, extend and further the changes put into motion by the "Pró-Saúde" Program. Its goals include enhancing the skills of faculty members and service professionals, promoting the inclusion of needed health services as a source of knowledge and research production in universities, and encouraging health care professionals to enter a teaching career.

We take this opportunity to invite the research and academic community - which have very competently elevated Brazilian Dentistry to the key position it holds today - to accept the challenge of investing their research excellence in the effort of improving the health care provided by SUS. 